\title{
Characterization of genetic variation and basis of inflammatory bowel disease in the Toll-like receptor 5 gene of the red wolf and the maned wolf
}

\author{
Lauren H. Henson ${ }^{1,2, *}$, Nucharin Songsasen ${ }^{3}$, Will Waddell ${ }^{4}$, Karen N. Wolf ${ }^{4}$, \\ Louise Emmons ${ }^{5}$, Susana Gonzalez ${ }^{6}$, Elizabeth Freeman ${ }^{7}$, Jesus Maldonado ${ }^{1}$ \\ ${ }^{1}$ Smithsonian Conservation Biology Institute, Center for Conservation and Evolutionary Genetics, 3001 Connecticut Ave. \\ NW Washington, DC 20008, USA \\ ${ }^{2}$ Environmental Science and Policy, George Mason University, 4400 University Dr., VA 22030, USA \\ ${ }^{3}$ Smithsonian Conservation Biology Institute, Center for Species Survival, 1500 Remount Rd., Front Royal, VA 22630, USA \\ ${ }^{4}$ Point Defiance Zoo and Aquarium, 5400 N Pearl St., Tacoma, WA 98407, USA \\ ${ }^{5}$ Smithsonian National Museum of Natural History, 10th St. \& Constitution Ave., NW Washington, DC 20560, USA \\ ${ }^{6}$ Instituto de Investigaciones Biológicas Clemente Estable, Ministerio de Educación y Cultura, Av. Italia 3318, CP 11600, \\ Montevideo, Uruguay \\ ${ }^{7}$ School of Integrative Studies, George Mason University, 4400 University Dr., VA 22030, USA
}

\begin{abstract}
Characterizing Toll-like receptors across taxa can lead to an increasingly accurate documentation of the evolutionary processes acting within this receptor class, as well as a greater understanding of the diseases associated with these receptors. This study examines 2 sequenced portions of the Toll-like receptor 5 (TLRS5) protein coding gene in 2 imperiled canid species: the Near Threatened maned wolf Chrysocyon brachyurus and the Critically Endangered red wolf Canis rufus, to characterize genetic variation and investigate the presence of single nucleotide polymorphisms (SNPs) previously associated with canine inflammatory bowel disease (IBD). Both maned and red wolves suffer from inflammatory bowel disease, threatening the sustainability of their crucial ex situ populations. Here we report novel polymorphic positions found in maned and red wolf TLR5, differences in variation with regard to nucleotide polymorphisms and resulting amino acid variation among maned wolves, red wolves, gray wolves and domestic dogs. Domestic dog SNPs associated with IBD were not found to be polymorphic in maned wolves and red wolves. Samples of both focal species and gray wolves lack the protective alleles present in many dog breeds, suggesting a potential genetic predisposition for IBD in these 2 wild canid species and a possible development of these protective alleles post domestication. This potential predisposition informs ex situ management practices and treatment for IBD.
\end{abstract}

KEY WORDS: Maned wolf $\cdot$ Red wolf $\cdot$ Toll-like receptor $5 \cdot$ Inflammatory bowel disease

\section{INTRODUCTION}

With the perils of habitat fragmentation, hunting and disease threatening in situ populations, the viability of ex situ populations is becoming increasingly relevant to the survival of many species. This study focuses on 2 canid species: the Critically Endangered

\footnotetext{
*Corresponding author: hensonlh@gmail.com
}

North American red wolf Canis rufus and the Near Threatened South American maned wolf Chrysocyon brachyurus (Kelly et al. 2008, Paula \& DeMatteo 2015). The red wolf, a canid that was once endemic to the southeastern United States, was declared extinct in the wild in 1980 due to habitat loss, hunting and the introgression of coyote genes (Fredrickson \& Government 2017. Open Access under Creative Commons by Attribution Licence. Use, distribution and reproduction are unrestricted. Authors and original publication must be credited. 
Hedrick 2006). Due to this introgression, the taxonomic status of the red wolf is highly controversial, with many studies indicating that the red wolf is a hybrid species between gray wolves and coyotes while others insisting it is a distinct species (Gese et al. 2015). The in situ population of red wolves was recovered with an intensive reintroduction program in North Carolina beginning in 1987, which has resulted in a population of approximately 75 individuals residing within the current $6000 \mathrm{~km}^{2}$ reintroduction area (Harrison 2014). The maned wolf faces also many challenges (Ratter et al. 1997, Deem \& Emmons 2005, Maia \& Gouveia 2002); as of 2008 the highly fragmented in situ maned wolf population was estimated at only 17000 mature individuals and is predicted to decline by at least $10 \%$ in the next $10 \mathrm{yr}$ (Paula et al. 2008).

Though the importance of viable ex situ populations for both maned and red wolves is becoming increasingly apparent, both species suffer health (Phillips \& Scheck 1991, Gilioli \& Silva 2000) and reproductive difficulties (Ginsberg 1994, Rodden et al. 1996, Rabon 2011, Johnson et al. 2014). Gastrointestinal disease is a major factor in mortalities in both red and maned wolves and has a high prevalence in both ex situ populations (Acton et al. 2000, Maia \& Gouveia 2002, Stirling et al. 2008, Seeley et al. 2016).

Inflammatory bowel disease (IBD), a common diagnosis in both species, is characterized by inflammation of the gastrointestinal tract (Craven et al. 2004). IBD is a multifaceted disorder (German et al. 2003) that has both microbial (Inness et al. 2007, Xenoulis et al. 2008, Simpson \& Jergens 2011) and genetic bases (Cario \& Podolsky 2000, Himmel et al. 2008) in other species. In the domestic dog Canis familiaris, the disease is linked to single nucleotide polymorphisms (SNPs) in the Toll-like receptor 4 (TLR4) and Toll-like receptor 5 (TLR5) genes (Kathrani et al. 2010), with 2 protective alleles against IBD identified in TLR5 across 38 different breeds (Kathrani et al. 2011).

Toll-like receptors (TLRs) are pattern recognition receptors essential to the functioning of the innate immune system that belong to a large family of interleukin 1 receptors (Akira 2003). These transmembrane receptors consist of a cytoplasmic Tollinterleukin 1 receptor (TIR) domain, responsible for downstream signal transduction, transmembrane domains and leucine rich repeat (LRR) extracellular domains (Kawai \& Akira 2010). These extracellular LRR motifs form a ligand-binding horseshoe shaped solenoid-like structure that recognizes pathogen associated molecular patterns (PAMP) (Leulier \& Lemaitre 2008, Bell et al. 2003) on the surface of bac- terial cells and helps to initiate an appropriate immune response through the production of cytokines (Akira et al. 2001). The pathogen recognition capability of TLRs make them an important component of the innate immune system and indicates a greater specificity for this system (Kawai \& Akira 2010). Six TLR families have been identified in vertebrates, with each family recognizing a specific class of PAMP (Roach et al. 2005). Receptors within the TLR5 family are responsible for detecting bacterial flagellin and mammalian TLR5 recognizes flagellin from both Gram-negative and Gram-positive bacteria (Hayashi et al. 2001).

Phylogenetic analysis places the origin of TLRs at 700 Myr (Leulier \& Lemaitre 2008). Studies attempting to identify the applicable model of evolution for these immune genes have oscillated between claiming that vertebrate TLRs are highly conserved because of the functional constraint of PAMPs (Roach et al. 2005) or that they are experiencing positive selection as a result of their constant interaction with rapidly evolving pathogens (Areal et al. 2011). Signatures of positive selection have been found in all mammalian TLRs across carnivores, lagomorphs, rodents, primates and artiodactyla, with non-viral TLRs having higher rates of positive selection than viral TLRs (Areal et al. 2011). In all species where adaptive selection has been identified, selective pressure is focused on the LRR extracellular domain because of its interaction with PAMPs (Areal et al. 2011) while a large portion of the TLR domain remains relatively conserved (Akira 2003). In TLR5, evidence of adaptive evolution has been found in the LRR pattern recognition extracellular domain (Wlasiuk et al. 2009, Smith et al. 2012) and a specific signature of adaptively evolving codons within this domain identified in domesticated mammals (Smith et al. 2012).

Toll-like receptors, because of their important role in the innate immune system, have been associated with many maladies. Mutations in TLRs, or their associated signaling pathways, have been linked to pneumococcal disease, systemic lupus erythematosus, chagas cardiomyopathy, malaria and tuberculosis in humans (Netea et al. 2012). Of particular interest to the present study, TLRs have also been implicated in the pathogenesis of gastrointestinal disorders (Netea et al. 2012). A healthy gut is characterized by its ability to regulate its immune response to food antigens and commensal bacteria while maintaining the ability to respond to pathogens. When this balance is disrupted, it can lead to inflammation and IBD. TLRs play an important role in maintaining this balance (Fukata \& Abreu 2008). In humans, poly- 
morphisms in the TLR2 gene as well as the TLR4 gene are more likely to be present in patients with colorectal cancer, and a TLR9 polymorphism has been associated with Crohn's disease. SNPs in TLRs 1, 2 and 6 associate with both ulcerative colitis and Crohn's disease (Fukata \& Abreu 2008), and genomic methods implicate TLRs 7 and 8 in celiac susceptibility (Netea et al. 2012). In mice, individuals that lack TLRs $2,4,5$ or 9 are more likely to develop colitis and have a higher mortality risk (Vijay-Kumar et al. 2007, Maloy \& Powrie 2011). Polymorphisms in the TLR5 gene are significantly associated with IBD in domestic dogs (Kathrani et al. 2010), with 2 protective SNPs identified across many different dog breeds (Kathrani et al. 2011).

Our aims in the present study were: (1) to characterize polymorphisms within 2 selected regions of the TLR5 gene in maned and red wolves; and (2) to determine the role of previously identified genetic markers for IBD in these 2 disease-prone species. We report novel polymorphisms in these previously unsampled threatened species and differing variability in TLR5 among 4 canid species: the maned wolf, red wolf, gray wolf and domestic dog. We also demonstrate a potential role for IBD SNPs in the pathogenesis of IBD within maned wolves and red wolves.

\section{MATERIALS AND METHODS}

Thirty-one maned wolves (24 ex situ and 7 in situ) and 15 red wolves were sampled for this study. Due to the opportunistic collection of samples, an Institutional Animal Care and Use Committee (IACUC) permit was not required by either the Smithsonian Conservation Biology Institute's IACUC committee or George Mason University's IACUC committee. Ex situ maned wolf samples were collected from individuals housed at the Smithsonian Conservation Biology Institute in Front Royal, VA and at 4 other Association of Zoos and Aquariums (AZA) accredited institutions. Maned wolf in situ samples represent populations situated in Bolivia $(\mathrm{N}=5)$, Argentina $(\mathrm{N}=1)$ and Brazil $(\mathrm{N}=1)$. Red wolf ex situ samples were collected from individuals at the Point Defiance Zoo and Aquarium in Tacoma, WA. For extant ex situ individuals of both species, blood was collected opportunistically during routine veterinary examinations. For deceased ex situ individuals, necropsy samples of liver were collected. In situ maned wolf samples were obtained from DNA extracted for previous studies investigating maned wolf genetic variability throughout their range (Gonzalez et al. 2015). Samples from Argentina and Brazil are from collections stored at the Conservation Genetics Laboratory at Departamento de Biodiversidad y Genética, at the Instituto de Investigaciones Biológicas Clemente Estable, Uruguay. Bolivian samples were obtained from populations in Noel Kempff Mercado National Park (Emmons et al. 2012).

DNA was extracted from whole blood and tissue using a Qiagen DNeasy Blood and Tissue Kit. For extraction from whole blood, Qiagen tissue lysis buffer was substituted for phosphate buffered saline (PBS) and DNA eluted in $100 \mu \mathrm{l}$ Buffer AE (10 mM Tris, 0.5 mM EDTA, pH 9.0) with no repeat elution. For tissue samples a $1 \mathrm{~g}$ tissue sliver was used for extraction, incubated at $56^{\circ} \mathrm{C}$ overnight for thorough lysis and eluted in $100 \mu \mathrm{l}$ Buffer AE with no repeat elution. DNA concentration and quality was measured using a Nanodrop 1000 Spectrophotometer (Thermo Scientific).

Two fragments surrounding the 3 IBD-associated SNPs in domestic dogs (Kathrani et al. 2010) were selected for amplification (Fig. 1). Both fragments are approximately $350 \mathrm{bp}$ (trimmed) with one fragment (Frag1) containing SNPs G22A (G727A in this study)

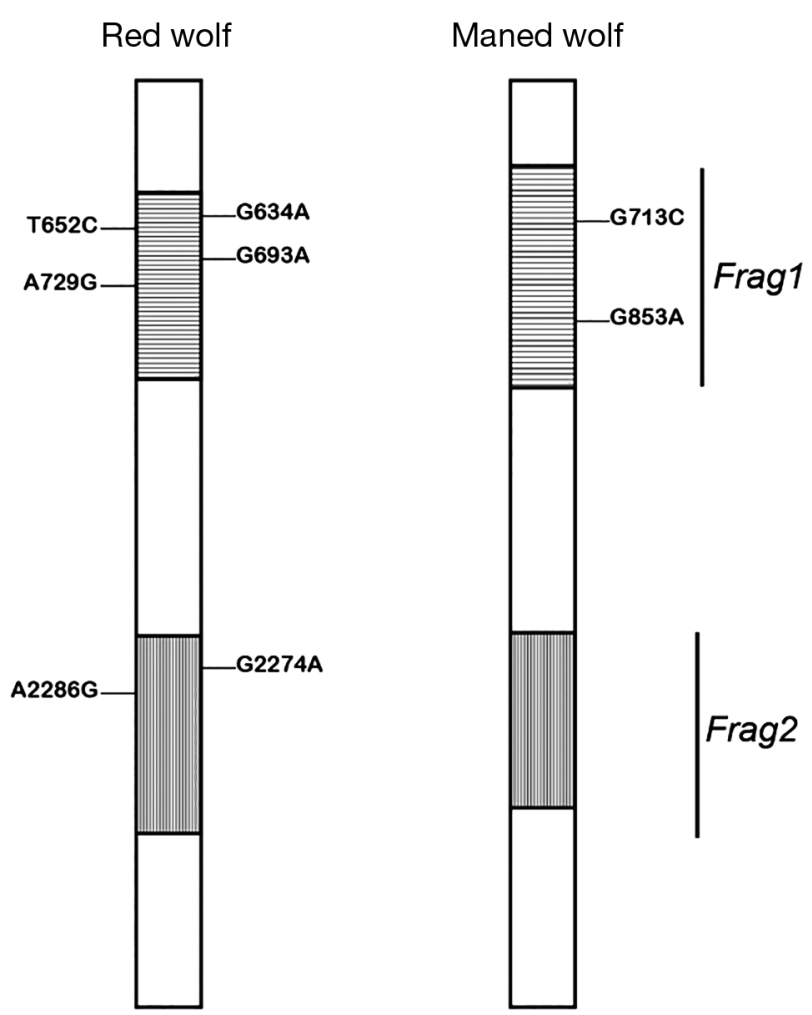

Fig. 1. Single nucleotide polymorphisms (SNPs) identified and found to be polymorphic in 2 fragments of the Toll-like receptor 5 gene in 29 maned wolves and 15 red wolves 
and C100T (C805T); and the second fragment (Frag2) containing SNP T1844C (C2549T). Primers (Fig. S1 in the Supplement at www.int-res.com/articles/suppl/ n032p135_supp.pdf) were designed to amplify these fragments using the Primer3 software (Untergasser et al. 2012) against domestic dog TLR5 (GenBank accession no. NW_0119176 and Ensembl accession no. ENSCAFT00000018059). AmpliTaq Gold Taq and buffer (Applied Biosystems) were used for all polymerase chain reactions (PCR), but cycling conditions varied between fragments (Fig. S2 in the Supplement). All reactions were run on a Biorad DNA engine Peltier thermal cycler tetrad (Bio-Rad). To inspect products for specific binding, and for the quality and quantity of amplified DNA, PCR products were run on a $1.5 \%$ agarose gel using GelRed dye (Biotium), a BioRad PowerPac Basic gel box and Tris-acetate (TAE) buffer. Gels were visualized using a MultiDoc-it Digital Imaging System (UVP).

Effective purification methods varied based on fragment and species due to the variation in size of nonspecific bands appearing in PCR products. For maned wolf samples nonspecific bands were typically less than $100 \mathrm{bp}$, and fragments were purified using $2 \mu \mathrm{l}$ EXOsapIT (Affymetrix) per $7 \mu \mathrm{l}$ of PCR product and incubated at $37^{\circ} \mathrm{C}$ for $25 \mathrm{~min}$ followed by $80^{\circ} \mathrm{C}$ for $15 \mathrm{~min}$. In red wolves, where contaminating products were typically larger than $100 \mathrm{bp}$, products were purified with solid phase reversible immobilization using carboxyl coated magnetic beads (SPRI beads). Samples were incubated for $10 \mathrm{~min}$ at room temp, then 5 min on a magnetic separation plate, subsequently washed with $100 \%$ ethanol and eluted with Qiagen Elution Buffer and 20\% Tween (EBT) (CSH protocol).

Purified products were sequenced using Big Dye Terminator v3.1 (Applied Biosystems). Samples were heated to $96^{\circ} \mathrm{C}$ for $2 \mathrm{~min}$, followed by 24 cycles of $96^{\circ} \mathrm{C}$ for $10 \mathrm{~s}, 50^{\circ} \mathrm{C}$ for $10 \mathrm{~s}$ and $60^{\circ} \mathrm{C}$ for $4 \mathrm{~min}$. Sequenced fragments were cleaned using a Sephadex G50 (GE Healthcare) column. After the application of water to dry Sephadex powder and the subsequent solidification of the powder, sequencing products were applied to the column, and centrifuged at $1454 \mathrm{~g}$ for $5 \mathrm{~min}$ in an Allegra X-15R plate centrifuge (VWR). Ten ml of Hi-Di Formamide (Life Technologies) was added to each well of sample and the plate was sequenced on an ABIPRISM3100 genetic analyzer (Life Technologies). All fragments were sequenced on both the forward and reverse strands to confirm polymorphic positions.

Sequenced fragments were aligned using the software program Sequencher 5.3 (Gene Codes) and in- spected manually for the presence of polymorphic positions. Subsequent contigs were aligned with available published domestic dog sequences for TLR5 (GenBank accession no. NW_0119176 and Ensembl accession no. ENSCAFT00000018059). SNP position was reported in reference to ENSCAFT00000018059. All polymorphic positions between domestic dog, red wolf and maned wolf sequences are reported in Fig. S3 in the Supplement. The number of SNPs in the 2 amplified regions of red wolf and maned wolf TLR5 were counted and compared to the number of SNPs in the same 2 regions in domestic dogs (Cuscó et al. 2014). Heterozygous positions were identified in Sequencher and corroborated by manual inspection. For heterozygous loci, the gametic phase was determined using the software PHASE (Stephens et al. 2001). Mean heterozygosity was calculated and compared between ex situ and in situ maned wolf samples using a Mann-Whitney $U$-test and between maned wolves, red wolves and previously published values for domestic dog and gray wolf (Cuscó et al. 2014) using a 1way ANOVA with a Bonferroni post hoc in SPSS. Nucleotide diversity $(\Theta)$ was calculated using a Tajima's test of neutrality in MEGA 5.22 (Tamura et al. 2011). To investigate patterns of selection, rates of non-synonymous (dN) and synonymous (dS) substitutions were calculated using both the codon-based HyPhy selection model and the Nei \& Gojobori (1986) method, with a Jukes-Cantor correction using MEGA software version 5.2.2 (Tamura et al. 2011).

Translation of fragment sequences into amino acids was performed in Sequencher (Genecodes). Amino acid change ratio was calculated by dividing the length of the resulting translation for each fragment by the number of amino acid changes created by non-synonymous SNPs. The amino acid change ratio for each fragment was compared to published data for domestic dog TLR5 (Cuscó et al. 2014). Protein domain predictions were made in SMART (Letunic et al. 2014) and used to identify domains encompassed by Frag1 and Frag2 as well as the domain type for identified SNPs. PROVEAN (Choi \& Chan 2015) was used to predict the functional impact of non-synonymous mutations by taking into consideration the amino acid sequence surrounding the residue of interest and classifying the mutation as either deleterious or neutral.

\section{RESULTS}

We detected 2 polymorphic positions in maned wolves, both in Frag1, and 6 polymorphic positions in 
red wolves with 4 in Frag1 and 2 in Frag2 (Table 1 \& Fig. 1). Inspection of previously published data (Cuscó et al. 2014) revealed that domestic dogs and gray wolves have more SNPs within these 2 TLR5 regions. Domestic dogs have 7 SNPs in Frag1 and 3 SNPs within Frag2 and gray wolves have 5 SNPs in Frag1 and 6 SNPs in Frag2 (Table 2). No polymorphic positions were shared between maned wolves and red wolves. Neither of the SNPs identified in maned wolves were found to be polymorphic in domestic dog and only 1 red wolf SNP was common to domestic dogs (A729G). A729G was also seen to be polymorphic within the published gray wolf SNP data set in addition to G2274A (Table 1).

In contrast with the finding of more SNPs in TLR5, dogs and gray wolves did not significantly differ from maned and red wolves in mean heterozygosity at these SNPs ( $p \geq 0.1)$ (Table 2). Tajima's $D$ nucleotide diversity measures for maned and red wolves found a greater average variability in maned wolves $(\Theta=$ $0.002599)$ than in red wolves $(\Theta=0.0013765)$, echoing the trend seen in heterozygosity, i.e. with more variability in maned wolves than red wolves. Within maned wolves there was no significant difference in mean heterozygosity between ex situ and in situ samples $(\mathrm{p} \geq 0.1)$.

A $Z$-test of selection for each species by fragment revealed no evidence of non-neutral selection for Frag1 in maned wolves and Frag2 in red wolves $(p \geq 0.05)$. The ratio of $d N / d S$ could not be calculated for these fragments because of the lack of synonymous mutations in each. In red wolf Frag1, although the codon based $Z$-test of selection showed only neutral selection ( $p \geq 0.05)$, HyPhy calculated $d N / d S$ at
0.146 , indicating a slight evidence of purifying selection (Table 3). Tests of selection were not performed for maned wolf Frag2 due to the lack of synonymous or non-synonymous mutations.

Tests of selection between species found evidence for both purifying and positive selection. The dN/dS ratio for Frag1 between maned and red wolves was 0.3362 , indicating purifying selection. The NeiGojobori method with a Jukes-Cantor correction for purifying selection also found purifying selection between these species in Frag1 $(p \leq 0.05)$ with the probability at 0.05 . For maned wolf and red wolf Frag2, strong evidence was found for positive selection $(\mathrm{p} \leq$ 0.05 ) with a codon based $Z$-test of selection using a Nei-Gojobori model with Jukes-Cantor correction yielding an overall probability of 0.03 (Table 3 ).

We used an amino acid change ratio to compare the effect of these described polymorphic sites on

Table 2. Comparison of single nucleotide polymorphism (SNP) number and SNP heterozygosity in maned wolves, red wolves, gray wolves and domestic dogs. Differences in mean heterozygosity between species were tested for significance by 1-way ANOVA with a Bonferroni post hoc test. Mean heterozygosity values for gray wolf and domestic dog were extrapolated from data published in Cuscó et al. (2014)

\begin{tabular}{|c|c|c|c|c|}
\hline Species & $\begin{array}{l}\text { Synony- } \\
\text { mous }\end{array}$ & $\begin{array}{l}\text { Imber of SNPs } \\
\text { Non- } \\
\text { synonymous }\end{array}$ & $\overline{T o t a l}$ & $\begin{array}{c}\text { Hetero- } \\
\text { zygosity } \\
(\text { mean } \pm \mathrm{SD})\end{array}$ \\
\hline Maned wolf & 0 & 2 & 2 & $0.44 \pm 0.09$ \\
\hline Red wolf & 4 & 2 & 6 & $0.23 \pm 0.10$ \\
\hline Gray wolf & 6 & 5 & 11 & $0.27 \pm 0.17$ \\
\hline Domestic dog & 6 & 4 & 10 & $0.26 \pm 0.15$ \\
\hline
\end{tabular}

Table 1. Polymorphic sites in Toll-like receptor 5 in 29 maned wolves and 15 red wolves. Single nucleotide polymorphism (SNP) position is in reference to ENSCAFT00000018059 and SNP ID includes allele 1, followed by the position and allele 2. Protein domain was predicted by SMART. PROVEAN function is based on prediction of non-synonymous SNPs only. Gray wolf and domestic dog allele frequencies were provided by Cuscó et al. (2014). Letters in bold indicate the changed allele between allele 1 and allele 2. ncp: no confident prediction; LRR: leucine rich repeat region

\begin{tabular}{|c|c|c|c|c|c|c|c|c|c|c|}
\hline \multirow[t]{2}{*}{ Position } & \multirow{2}{*}{$\begin{array}{l}\text { SNP } \\
\text { ID }\end{array}$} & \multicolumn{2}{|c|}{- Codon -} & \multirow{2}{*}{$\begin{array}{l}\text { Amino acid } \\
\text { substitution }\end{array}$} & \multirow{2}{*}{$\begin{array}{l}\text { Protein } \\
\text { domain }\end{array}$} & \multirow{2}{*}{$\begin{array}{c}\text { PROVEAN- } \\
\text { output }\end{array}$} & \multirow[b]{2}{*}{$\begin{array}{l}\text { Maned } \\
\text { wolf }\end{array}$} & \multicolumn{2}{|c|}{ Allele frequency } & \multirow{2}{*}{$\begin{array}{l}\text { Domestic } \\
\text { dog }\end{array}$} \\
\hline & & Allele 1 & Allele 2 & & & & & $\begin{array}{l}\text { Red } \\
\text { wolf }\end{array}$ & $\begin{array}{l}\text { Gray } \\
\text { wolf }\end{array}$ & \\
\hline 634 & G634A & GTC & ATC & val/ile & nсp & Neutral & G(1) & $\mathrm{G}(0.86)$ & & $\mathrm{G}(1)$ \\
\hline 652 & T652C & TGG & CGG & $\operatorname{trp} / \arg ^{\mathrm{a}}$ & ncp & Neutral & $\mathrm{T}(0)$ & $\mathrm{T}(0.73)$ & & $\mathrm{T}(1)$ \\
\hline 693 & G693A & CCG & CCA & pro/pro & ncp & & G(1) & $\mathrm{G}(0.91)$ & & $\mathrm{G}(1)$ \\
\hline 713 & G713C & CGC & $\mathrm{CCC}$ & $\mathrm{arg} / \mathrm{pro}^{\mathrm{a}}$ & ncp & Neutral & $\mathrm{G}(0.75)$ & $\mathrm{G}(1)$ & & $\mathrm{G}(1)$ \\
\hline 729 & A729G & GCA & GCG & ala/ala & ncp & & $\mathrm{A}(0)$ & $\mathrm{A}(0.82)$ & $\mathrm{A}(0.4)$ & $\mathrm{A}(0.39)$ \\
\hline 853 & G853A & GTC & ATC & ile/val $^{\mathrm{a}}$ & ncp & Neutral & $\mathrm{G}(0.54)$ & $\mathrm{G}(0)$ & & $\mathrm{G}(0)$ \\
\hline 2274 & G2274A & CGG & CGA & arg/arg & LRR & & $\mathrm{G}(1)$ & $\mathrm{G}(0.92)$ & $\mathrm{G}(0.76)$ & $\mathrm{G}(1)$ \\
\hline 2286 & A2286G & GCA & GCG & ala/ala & LRR & & $\mathrm{A}(0)$ & $\mathrm{A}(0.92)$ & & $\mathrm{A}(0)$ \\
\hline
\end{tabular}


Table 3. Ratios of rates of non-synonymous (dN) and synonymous (dS) substitutions and results of tests for neutral, purifying and positive selection in maned wolves (MW) and red wolves (RW). dN/dS ratios are shown for fragments with both non-synonymous and synonymous changes only. MW Frag2 is not included due to lack of variable sites. Selection tests were codonbased Z-tests, using the Nei-Gojobori method with Jukes-Cantor correction. Selection probabilities are calculated as the probability of rejecting the null hypothesis of $\mathrm{dN}=\mathrm{dS}$ (neutral selection), and as the probability of rejecting the null hypothesis of $\mathrm{dN}=\mathrm{dS}$ for $\mathrm{dN}<\mathrm{dS}$ and $\mathrm{dN}>\mathrm{dS}$ (purifying and positive selection, respectively). Significant values are shown in bold

\begin{tabular}{|c|c|c|c|c|c|c|c|}
\hline \multirow{3}{*}{ Species/Fragment } & \multirow[t]{3}{*}{$\mathrm{dN} / \mathrm{dS}$} & \multicolumn{6}{|c|}{ Selection test } \\
\hline & & \multicolumn{2}{|c|}{ Neutral selection } & \multicolumn{2}{|c|}{ Purifying selection } & \multicolumn{2}{|c|}{ Positive selection } \\
\hline & & Probability & Test statistic & Probability & Test statistic & Probability & Test statistic \\
\hline MW Frag1 & & 0.17 & 1.39 & 1.00 & -1.35 & 0.08 & 1.43 \\
\hline RW Frag1 & 0.146 & 0.27 & 1.11 & 0.13 & 1.15 & 1.00 & -1.14 \\
\hline RW Frag2 & & 0.14 & 1.48 & 1.00 & -1.40 & 0.07 & 1.45 \\
\hline MW and RW Frag1 & 0.3362 & 0.09 & 1.73 & 0.05 & -1.67 & 1.00 & -1.69 \\
\hline MW and RW Frag2 & & 0.07 & -1.81 & 1.00 & -1.76 & 0.03 & 1.88 \\
\hline
\end{tabular}

resulting proteins. Domestic dogs and gray wolves had a higher amino acid change ratio than either maned or red wolves, which may be due to a population bottleneck in red wolves or to a higher level of evolutionary conservation of the TLR5 locus in both threatened species (Table 4).

We predicted protein domain structure for the selected fragments. Frag1 for both maned wolves and red wolves consisted of 3 unknown domains and 2 low complexity regions. Frag2 consisted of 3 LRR regions, 1 leucine rich repeat C-terminal (LRR-CT) region and 1 unknown region. All SNPs in Frag1 in both species were in areas with unknown SMART predictions while both SNPs in red wolf Frag2 were in the LRR region (Table 1).

Both maned wolf SNPs were non-synonymous compared with 2 of 6 red wolf SNPs, 5 of 11 gray wolf polymorphisms and 4 of 10 domestic dog polymorphisms. All non-synonymous maned wolf and red wolf SNPs were in Frag1 while domestic dog and gray wolf non-synonymous SNPs were more evenly distributed between the 2 fragments.

Table 4. Comparison of amino acid change ratio in maned wolf, red wolf, gray wolf and domestic dog TLR5. Protein length is shown as the number of amino acids. The amino acid ratio is calculated as the number of amino acid changes caused by non-synonymous SNPs divided by the protein length. Amino acid change ratios for gray wolf and domestic dog were extrapolated from data published in Cuscó et al. (2014)

\begin{tabular}{|lcc|}
\hline Species & Protein length & Amino acid change ratio \\
\hline Maned wolf & 288 & $1 / 144$ \\
Red wolf & 279 & $1 / 139.5$ \\
Gray wolf & 288 & $1 / 57.6$ \\
Domestic dog & 288 & $1 / 72$ \\
\hline
\end{tabular}

The functional impact of these non-synonymous SNPs was tested using PROVEAN and all identified red wolf and maned wolf non-synonymous SNPs were shown to have a neutral effect on protein function (Table 1). By comparison, 3 non-synonymous SNPs in domestic dogs and 4 gray wolf non-synonymous SNPs present within Frag1 and Frag2 were reported to have a probably or possibly damaging impact on protein function (Cuscó et al. 2014). One of these SNPs is T1844C, a SNP previously associated with domestic dog IBD (Kathrani et al. 2010), which was shown to be deleterious (Cuscó et al. 2014). All identified domestic dog and gray wolf SNPs (Cuscó et al. 2014) with a potential functional impact were not present as polymorphic positions in maned or red wolves.

The SNPs identified as associated with domestic $\operatorname{dog}$ IBD (G727A, C805T and C2549T) were not polymorphic in maned or red wolves. However, both red wolves and maned wolves lacked the protective $\mathrm{T}$ allele in C805T and C2549T and the risk allele A in G727A (Fig. 2). Gray wolves also lack these protective alleles (Cuscó et al. 2014) indicating that the non-protective allele $\mathrm{C}$ is potentially ancestral. PROVEAN predictions show that the deleterious impact of the leucine to serine amino acid change in the C2549T SNP is retained in maned wolves and red wolves (Table 5).

\section{DISCUSSION}

TLRs are increasingly becoming a target of research due to their crucial roles as sentinels of the innate immune system and their associations with many common and debilitating diseases in both humans and in animal models (Netea et al. 2012). 


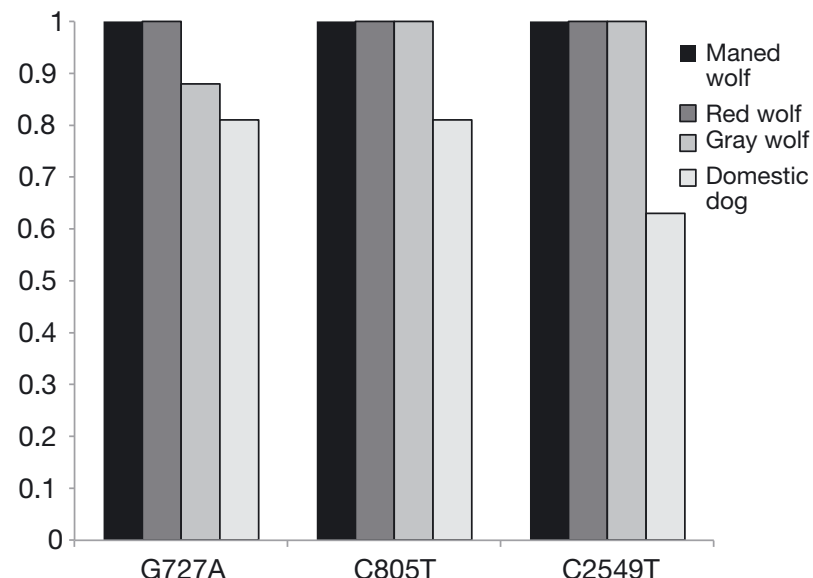

Fig. 2. Observed allele frequency for single nucleotide polymorphisms (SNPs) associated with inflammatory bowel disease (IBD) (alleles G in G727A and C in C805T and C2549T) in maned wolves and red wolves. Allele frequencies for gray wolf and domestic dog IBD-associated SNPs were provided by Cuscó et al. (2014)

Our characterization of the TLR5 locus is the first description of polymorphism in this locus in 2 threatened canid species in need of careful captive management. A greater understanding of the genetic diversity of these immune genes should contribute to maintaining healthy ex situ populations.

The larger number of SNPs in domestic dog and gray wolf and the lack of significant difference among mean heterozygosity in all 4 species implies that these regions may be more variable in gray wolf and domestic dog but that heterozygosity has been maintained over evolutionary time. This would suggest a role for balancing selection in this system, which has been implicated in the evolution of innate immunity in humans (Ferrer-Admetlla et al. 2008). The higher amino acid change ratio in domestic dogs and gray wolves indicates that the observed genetic variation results in changes in amino acid composi- tion within the 2 TLR5 regions. Future studies should screen for variation across a larger number of canid species and individuals to confirm levels of variation across this family.

Consistent with reports that identify the LRR region of TLR5 as a site under adaptive selection due to its direct interaction with evolving pathogens (Areal et al. 2011), signatures of adaptive selection were detected within the LRR here between maned and red wolves, indicating that this ligand binding pocket is potentially adapting to compete with evolving microbes, as in other mammalian species. However this hypothesis needs to be further tested by conducting comparative microbiome analyses in maned and red wolves. The higher number of SNPs in both gray wolf and domestic dog and their higher propensity to be non-synonymous and damaging, is suggestive of deleterious allele accumulation in this region of TLR5. Deleterious allele accumulation is seen in domestic dogs and gray wolves and could be a result of a previously documented bottleneck in domestic dogs and in the European population of wolves referenced in this study (Cruz et al. 2008, Cuscó et al. 2014, Pilot et al. 2014). Some of the non-damaging mutations found in maned and red wolves could be products of adaptation to different microbial and dietary environments that require a species-specific function of TLR5 (Bergman et al. 2010). The complete lack of overlap in variable sites among all 4 canid species and the conservation of just 1 polymorphic position among red wolves, gray wolves and domestic dogs further suggests a potential species-specific function for TLR5 in maned wolves and red wolves, as is seen in other species (Werling et al. 2009).

The finding of less variation in maned and red wolf TLR5 fragments than in domestic dog and gray wolf is supported by: (1) the low SNP number in maned wolves and red wolves compared to domestic dogs and gray wolves, (2) the neutral functional impact of observed non-synonymous SNPs, (3) the low amino

Table 5. Polymorphic sites associated with inflammatory bowel disease (IBD) in maned wolves, red wolves, gray wolves and domestic dogs. SNP position is in reference to ENSCAFT00000018059. In all 3 cases amino acid substitution was non-synonymous. Protein domain was predicted by SMART. PROVEAN function is based on prediction of non-synonymous SNPs only. Gray wolf and domestic dog allele frequencies were provided by Cuscó et al. (2014). ncp: no confident prediction; LRR CT: leucine rich $\mathrm{C}$ terminal region

\begin{tabular}{|c|c|c|c|c|c|c|c|c|c|c|}
\hline \multirow{2}{*}{ Position } & \multirow{2}{*}{$\begin{array}{l}\text { SNP } \\
\text { ID }\end{array}$} & \multicolumn{2}{|c|}{- Codon -} & \multirow{2}{*}{$\begin{array}{l}\text { Amino acid } \\
\text { substitution }\end{array}$} & \multirow{2}{*}{$\begin{array}{l}\text { Protein } \\
\text { domain }\end{array}$} & \multirow{2}{*}{$\begin{array}{l}\text { PROVEAN } \\
\text { output }\end{array}$} & \multirow[b]{2}{*}{$\begin{array}{l}\text { Maned } \\
\text { wolf }\end{array}$} & \multicolumn{3}{|c|}{ Allele frequency } \\
\hline & & Allele 1 & Allele 2 & & & & & $\begin{array}{l}\text { Red } \\
\text { wolf }\end{array}$ & $\begin{array}{l}\text { Gray } \\
\text { wolf }\end{array}$ & $\begin{array}{l}\text { Domestic } \\
\text { dog }\end{array}$ \\
\hline 727 & G727A & GCG & $\mathrm{ACG}$ & ala/thr & nсp & Neutral & $\mathrm{G}(1)$ & $\mathrm{G}(1)$ & $\mathrm{G}(0.88)$ & $\mathrm{G}(0.81)$ \\
\hline 805 & C805T & CGC & TGC & arg/cys & nсp & Neutral & $\mathrm{C}(1)$ & $\mathrm{C}(1)$ & $\mathrm{C}(0.99)$ & $\mathrm{C}(0.81)$ \\
\hline 2549 & $\mathrm{C} 2549 \mathrm{~T}$ & TCG & TTG & ser/leu & LRR CT & Deleterious & $\mathrm{C}(1)$ & $\mathrm{C}(1)$ & $\mathrm{C}(0.98)$ & $\mathrm{C}(0.63)$ \\
\hline
\end{tabular}


acid change ratio and the low number of SNPs in both Frag1 and the putatively variable LRR region in Frag2. This potential within-species conservation supports previous studies that identify TLRs as a conserved class of proteins (Roach et al. 2005). The finding of distinct variation between species, especially in the ligand binding site, points to a potential specificity of function of TLR5 in maned wolves and red wolves, likely influenced by differences in their microbial environments (Takeda et al. 2003). The implications of these findings for studies of the adaptive nature of TLR5 are limited by the lack of a robust demographic analysis that would incorporate the distinct recent evolutionary histories of these 4 species. That said, we chose samples that capture the full range of diversity in the current red wolf and maned wolf populations, especially through the inclusion of in situ maned wolf samples.

Within these 2 now characterized fragments lie the 3 SNPs previously associated with domestic dog IBD (G727A, C805T and C2549; Kathrani et al. 2010). The non-polymorphic nature of these SNPs in maned wolves and red wolves makes them unsuitable as diagnostic markers for inflammatory bowel disease. However, all sampled ex situ and in situ maned wolves and red wolves lacked the protective thymine present in the alleles validated across all dog breeds (C805T and C2549T; Kathrani et al. 2011), suggesting that both taxa may carry a genetic predisposition to IBD. The high prevalence of IBD in captive populations of both species, and the retention of the deleterious effect of the C2549T SNP, are further evidence for this predisposition. A large population of gray wolves also lacks the protective allele $\mathrm{T}$ in both C805T and C2549T, indicating that the non-protective allele $\mathrm{C}$ is ancestral and that the $\mathrm{T}$ allele emerged in domestic dogs (Cuscó et al. 2014). The lack of the domestic dog protective alleles in these threatened canids is not enough to prove a genetic predisposition to IBD. Future work is needed to correlate standardized molecular and pathological markers of disease status with these genetic findings.

Recent work on dog domestication has identified a host of genes containing a signature of domestication, typically in mutations that allow dogs to better adapt to association with humans (Wang et al. 2013). Adaptation to a starch-based diet plays an essential role in domestication and provides a relevant link to IBD (Axelsson et al. 2013). Since TLR5 recognizes bacterial flagellin, a shift in gut microbiome composition as a result of diet change (Middelbos et al. 2010) can result in an inappropriate hypo- or hyper-activation of the TLR pathway and lead to inflammation
(Cario 2010). It is possible that the $\mathrm{T}$ allele in domestic dog C805T and C2549T developed as a protection against this type of inflammation.

Ex situ maned and red wolves in the United States are primarily fed artificial starch-based diets (Harrison 2014, Songsasen 2014) in contrast to their in situ omnivorous and carnivorous diets, respectively (Paradiso \& Nowak 1972, Aragona \& Setz 2001). Differences in diet between captive and wild individuals can result in changes to the intestinal microbial community (Turnbaugh et al. 2009). Feeding ex situ wild canids diets developed for domestic dogs may promote the development of microbial communities more similar to those of domestic animals than to those of their in situ conspecifics (De Jesús-Laboy et al. 2011). Since TLR5 specifically recognizes bacterial flagellin, a dog-like microbiome interacting with a maned or red wolf TLR evolutionarily adapted to the native microbiome of these species could result in a hypo- or hyper-activation of this portion of the innate immune system. While dogs have had about 10000 yr (Wang et al. 2013, Freedman et al. 2014) since the domestication of grains to adapt to a starchbased diet, maned and red wolves have been managed by species survival plans in captivity for only 30 and $35 \mathrm{yr}$, respectively. Adaptation to starch-based diets should not be a goal of captive breeding programs and should be avoided at all costs for any ex situ programs that may eventually result in reintroduction. With further investigation, this relationship between putative genetic predisposition, and inappropriate diet in combination with the resulting foreign microbial community could explain the high prevalence of IBD in ex situ maned and red wolves.

Future studies should focus on documenting and correlating the gastrointestinal microbiome compositions of ex situ and in situ maned wolves and red wolves with clinical, histopathological and serum markers of IBD. Further characterizations of the full sequence of TLR5 for these sampled populations of maned and red wolves, in addition to other canid species, could inform the evolutionary nature of TLRs within the Canis genus. Additionally, with more research on the accurate diagnosis of maned and red wolf IBD, future work can focus on correlating the TLR5 SNPs identified in domestic dogs with a definitive IBD diagnosis in maned and red wolves.

Acknowledgements. We thank the Center for Conservation and Evolutionary Genetics for their support throughout this project, specifically Nancy McInerney for her invaluable guidance, Lilly Parker for her advice, Nandanevi Cortes for training in PHASE, and all graduate students, postdocs, con- 
tractors and fellows that participated in the writing group for their assistance with editing. Priscilla Joyner was instrumental in assisting with sample collection and advice regarding IBD pathogenesis. Additionally we thank Olga Francino for providing information regarding SNP allele frequencies for the gray wolf population and Aarti Kathrani for answering questions regarding amplification protocols. We also acknowledge the red wolf and maned wolf species survival plan groups for their assistance with samples and openness to implement suggested management changes. Louis Emmons' maned wolf research in Bolivia was in collaboration with the Museo de Historia Natural Noel Kempff Mercado, Universidad Gabriel René Moreno, Santa Cruz, Bolivia under permits from Dirección General de Biodiversidad and the Servicio Nacional de Áreas Protegidas of the Estado Plurinacional de Bolivia, and it was supported by the Smithsonian Institution, the National Geographic Society, and the Wildlife Conservation Society. S.G.'s research was supported by PEDECIBA, CSIC-UdelaR from Uruguay.

\section{LITERATURE CITED}

Acton AE, Munson L, Waddell WT (2000) Survey of necropsy results in captive red wolves (Canis rufus), 1992-1996. J Zoo Wildl Med 31:2-8

Akira S (2003) Toll-like receptor signaling. J Biol Chem 278: 38105-38108

Akira S, Takeda K, Kaisho T (2001) Toll-like receptors: critical proteins linking innate and acquired immunity. Nat Immunol 2:675-680

Aragona M, Setz EZF (2001) Diet of the maned wolf, Chrysocyon brachyurus (Mammalia: Canidae), during wet and dry seasons at Ibitipoca State Park, Brazil. J Zool (Lond) 254:131-136

Areal H, Abrantes J, Esteves PJ (2011) Signatures of positive selection in Toll-like receptor (TLR) genes in mammals. BMC Evol Biol 11:368

Axelsson E, Ratnakumar A, Arendt ML, Maqbool K and others (2013) The genomic signature of dog domestication reveals adaptation to a starch-rich diet. Nature 495: 360-364

Bell JK, Mullen GED, Leifer CA, Mazzoni A, Davies DR, Segal DM (2003) Leucine-rich repeats and pathogen recognition in Toll-like receptors. Trends Immunol 24: 528-533

* Bergman IM, Rosengren JK, Edman K, Edfors I (2010) European wild boars and domestic pigs display different polymorphic patterns in the Toll-like receptor (TLR) 1, TLR2, and TLR6 genes. Immunogenetics 62:49-58

* Cario E (2010) Toll-like receptors in inflammatory bowel diseases: a decade later. Inflamm Bowel Dis 16: 1583-1597

Cario E, Podolsky DK (2000) Differential alteration in intestinal epithelial cell expression of Toll-like receptor 3 (TLR3) and TLR4 in inflammatory bowel disease. Infect Immun 68:7010-7017

Choi Y, Chan AP (2015) PROVEAN web server: a tool to predict the functional effect of amino acid substitutions and indels. Bioinformatics 31:2745-2747

* Craven M, Simpson JW, Ridyard AE, Chandler ML (2004) Canine inflammatory bowel disease: retrospective analysis of diagnosis and outcome in 80 cases (1995-2002). J Small Anim Pract 45:336-342

* Cruz F, Vilà C, Webster MT (2008) The legacy of domestica- tion: accumulation of deleterious mutations in the dog genome. Mol Biol Evol 25:2331-2336

* Cuscó A, Sánchez A, Altet L, Ferrer L, Francino O (2014) Non-synonymous genetic variation in exonic regions of canine Toll-like receptors. Canine Genet Epidemiol 1:11

*De Jesús-Laboy KM, Godoy-Vitorino F, Piceno YM, Tom LM and others (2011) Comparison of the fecal microbiota in feral and domestic goats. Genes (Basel) 3:1-18

* Deem SL, Emmons LH (2005) Exposure of free-ranging maned wolves (Chrysocyon brachyurus) to infectious and parasitic disease agents in the Noel Kempff Mercado National Park, Bolivia. J Zoo Wildl Med 36:192-197

Emmons L (2012) The maned wolves of Noel Kempff Mercado National Park. Smithson Contrib Zool 639:1-135

*Ferrer-Admetlla A, Bosch E, Sikora M, Marquès-Bonet T and others (2008) Balancing selection is the main force shaping the evolution of innate immunity genes. J Immunol 181:1315-1322

Fredrickson RJ, Hedrick PW (2006) Dynamics of hybridization and introgression in red wolves and coyotes. Conserv Biol 20:1272-1283

* Freedman AH, Gronau I, Schweizer RM, Ortega-Del Vecchyo D and others (2014) Genome sequencing highlights the dynamic early history of dogs. PLOS Genet 10: e1004631

Fukata M, Abreu MT (2008) Role of Toll-like receptors in gastrointestinal malignancies. Oncogene 27:234-243

* German AJ, Hall E, Day M (2003) Chronic intestinal inflammation and intestinal disease in dogs. J Vet Intern Med 17:8-20

Gese EM, Knowlton FF, Adams JR, Beck K and others (2015) Managing hybridization of a recovering endangered species: the red wolf Canis rufus as a case study. Curr Zool 61:191-205

Gilioli R, Silva FA (2000) Frequency of parasites and Salmonella infection in captive maned-wolf, Chrysocyon brachyurus, kept in zoos at the State of São Paulo, Brazil. Arq Bras Med Vet Zootec 52:337-341

Ginsberg JR (1994) Captive breeding, reintroduction and the conservation of canids. In: Olney PJS, Mace GM, Feistner ATC (eds) Creative Conservation. Springer, Dordrecht,p 365-383

González S, Cosse M, Rosario Franco M, Emmons L and others (2015) Population structure of mtDNA variation due to Pleistocene fluctuations in the South American maned wolf (Chrysocyon brachyurus, Illiger, 1815): management units for conservation. J Hered 106:459-468

Harrison R (2014) Status of the Red Wolf Program. Red Wolf Species Survival Plan meeting, 24 July 2014, Akron Zoo, Akron, $\mathrm{OH}$

Kayashi F, Smith KD, Ozinsky A, Hawn TR and others (2001) The innate immune response to bacterial flagellin is mediated by Toll-like receptor 5. Nature 410:1099-1103

*Himmel ME, Hardenberg G, Piccirillo CA, Steiner TS, Levings MK (2008) The role of T-regulatory cells and Tolllike receptors in the pathogenesis of human inflammatory bowel disease. Immunology 125:145-153

* Inness VL, McCartney AL, Khoo C, Gross KL, Gibson GR (2007) Molecular characterisation of the gut microflora of healthy and inflammatory bowel disease cats using fluorescence in situ hybridisation with special reference to Desulfovibrio spp. J Anim Physiol Anim Nutr (Berl) 91: 48-53

Johnson AEM, Freeman EW, Wildt DE, Songsasen N (2014) Spermatozoa from the maned wolf (Chrysocyon brachy- 
urus) display typical canid hyper-sensitivity to osmotic and freezing-induced injury, but respond favorably to dimethyl sulfoxide. Cryobiology 68:361-370

Kathrani A, House A, Catchpole B, Murphy A, German A, Werling D, Allenspach K (2010) Polymorphisms in the Tlr4 and Tlr5 gene are significantly associated with inflammatory bowel disease in German shepherd dogs. PLOS ONE 5:e15740

Kathrani A, House A, Catchpole B, Murphy A, Werling D, Allenspach K (2011) Breed-independent toll-like receptor 5 polymorphisms show association with canine inflammatory bowel disease. Tissue Antigens 78: 94-101

Kawai T, Akira S (2010) The role of pattern-recognition receptors in innate immunity: update on Toll-like receptors. Nat Immunol 11:373-384

Kelly BT, Beyer A, Phillips MK (2008) Canis rufus. IUCN Red List of Threatened Species 2008: e.T3747A10057394 (accessed June 2016)

Letunic I, Doerks T, Bork P (2014) SMART: recent updates, new developments and status in 2015. Nucleic Acids Res 43:D257-D260

Leulier F, Lemaitre B (2008) Toll-like receptors — taking an evolutionary approach. Nat Rev Genet 9:165-178

Maia OB, Gouveia AMG (2002) Birth and mortality of maned wolves Chrysocyon brachyurus (Illiger, 1811) in captivity. Braz J Biol 62:25-32

Maloy KJ, Powrie F (2011) Intestinal homeostasis and its breakdown in inflammatory bowel disease. Nature 474 : 298-306

Middelbos IS, Vester Boler BM, Qu A, White BA, Swanson KS, Fahey GC Jr (2010) Phylogenetic characterization of fecal microbial communities of dogs fed diets with or without supplemental dietary fiber using 454 pyrosequencing. PLOS ONE 5:e9768

Nei M, Gojobori T (1986) Simple methods for estimating the numbers of synonymous and nonsynonymous nucleotide substitutions. Mol Biol Evol 5:418-426

Netea MG, Wijmenga C, O'Neill LAJ (2012) Genetic variation in Toll-like receptors and disease susceptibility. Nat Immunol 13:535-542

* Paradiso JL, Nowak RM (1972) Canis rufus. Mamm Species 22, 22:1-4

Paula RC, Medici P, Morato RG (2008) Maned wolf action plan: population and habitat viability assessment. Edições Ibama, Brasilia

*Paula RC, DeMatteo K (2015) Chrysocyon brachyurus. (Errata version published in 2016). IUCN Red List of Threatened Species 2015: e.T4819A88135664 (accessed June 2016)

Phillips MK, Scheck J (1991) Parasitism in captive and reintroduced red wolves. J Wildl Dis 27:498-501

* Pilot M, Greco C, vonHoldt BM, Jędrzejewska B and others (2014) Genome-wide signatures of population bottlenecks and diversifying selection in European wolves. Heredity 112:428-442

Rabon DRJ (2011) Factors affecting reproduction in the red wolf (Canis rufus). PhD thesis, NC State University, Raleigh, NC

Ratter JA, Ribeiro JF, Bridgewater S (1997) The Brazilian

Editorial responsibility: David Richardson,

Norwich, UK
Cerrado vegetation and threats to its biodiversity. Ann Bot (Lond) 80:223-230

Koach JC, Glusman G, Rowen L, Kaur A and others (2005) The evolution of vertebrate Toll-like receptors. Proc Natl Acad Sci USA 102:9577-9582

* Rodden MD, Sorenson LG, Sherr A, Kleiman DG (1996) Use of behavioral measures to assess reproductive status in maned wolves (Chrysocyon brachyurus). Zoo Biol 15: 565-585

Seeley KE, Garner MM, Waddell WT, Wolf KN (2016) A survey of diseases in captive red wolves (Canis rufus), $1997-$ 2012. J Zoo Wildl Med

Simpson KW, Jergens AE (2011) Pitfalls and progress in the diagnosis and management of canine inflammatory bowel disease. Vet Clin N Am Small Anim Pract 41: 381-398

S Smith SA, Jann OC, Haig D, Russell GC, Werling D, Glass EJ, Emes RD (2012) Adaptive evolution of Toll-like receptor 5 in domesticated mammals. BMC Evol Biol 12:122

Songsasen N (2014) The Maned Wolf Species Survival Plan. Maned Wolf Species Survival Plan Meeting, Smithsonian Conservation Biology Institute, Front Royal, VA

Stephens M, Smith NJ, Donnelly P (2001) A new statistical method for haplotype reconstruction from population data. Am J Hum Genet 68:978-989

Stirling J, Griffith M, Blair I, Cormican M and others (2008) Prevalence of gastrointestinal bacterial pathogens in a population of zoo animals. Zoonoses Public Health 55: 166-172

Takeda K, Kaisho T, Akira S (2003) Toll-like receptors. Annu Rev Immunol 21:335-376

Tamura K, Peterson D, Peterson N, Stecher G, Nei M, Kumar S (2011) MEGA5: Molecular evolutionary genetics analysis using maximum likelihood, evolutionary distance, and maximum parsimony methods. Mol Biol Evol 28: 2731-2739

* Turnbaugh PJ, Ridaura VK, Faith JJ, Rey FE, Knight R, Gordon JI (2009) The effect of diet on the human gut microbiome: a metagenomic analysis in humanized gnotobiotic mice. Sci Transl Med 1:6ra14

Untergasser A, Cutcutache I, Koressar T, Ye J, Faircloth BC, Remm M, Rozen SG (2012) Primer3-new capabilites and interfaces. Nucleic Acids Res 40:e115

Vijay-Kumar M, Sanders CJ, Taylor RT, Kumar A and others (2007) Deletion of TLR5 results in spontaneous colitis in mice. J Clin Invest 117:3909-3921

Wang G, Zhai W, Yang H, Fan R and others (2013) The genomics of selection in dogs and the parallel evolution between dogs and humans. Nat Commun 4:1860

* Werling D, Jann OC, Offord V, Glass EJ, Coffey TJ (2009) Variation matters: TLR structure and species-specific pathogen recognition. Trends Immunol 30:124-130

Wlasiuk G, Khan S, Switzer WM, Nachman MW (2009) A history of recurrent positive selection at the Toll-like receptor 5 in primates. Mol Biol Evol 26:937-949

Xenoulis PG, Palculict B, Allenspach K, Steiner JM, Van House AM, Suchodolski JS (2008) Molecular-phylogenetic characterization of microbial communities imbalances in the small intestine of dogs with inflammatory bowel disease. FEMS Microbiol Ecol 66:579-589

Submitted: April 12, 2016; Accepted: November 14, 2016

Proofs received from author(s): January 23, 2017 